\title{
Digital Technologies and Complexes for Provision of Vehicular Traffic Safety
}

\author{
Igor Vorozheikin \\ Department of Land Transport \\ Technological Machines \\ Saint Petersburg State University of \\ Architecture and Civil Engineering \\ Saint Petersburg, Russia \\ igor.vorozheikin@mail.ru
}

\author{
Alexey Marusin \\ Department of Technical Operation of \\ Vehicles \\ Saint Petersburg State University of \\ Architecture and Civil Engineering \\ Saint Petersburg, Russia \\ Department of Machine Parts and \\ Theory of Mechanisms \\ Moscow Automobile and Road \\ Construction State Technical \\ University (MADI) \\ Moscow, Russia \\ 89312555919@mail.ru
}

\author{
Ilya Brylev \\ Department of Land Transport \\ Technological Machines \\ Saint Petersburg State University of \\ Architecture and Civil Engineering \\ Saint Petersburg, Russia \\ ilya2104@mail.ru
}

\author{
Victoria Vinogradova \\ Department of Construction Economics \\ and Housing and Utility Infrastructure \\ Saint Petersburg State University of \\ Architecture and Civil Engineering \\ Saint Petersburg, Russia \\ vittoria.vinogradova@gmail.com
}

Abstract-One of the most important tasks being implemented at the state level for improving safety and ecological properties of the transport domain of the country is reduction of negative influence of permanently increasing quantity of motor vehicles. On account of functioning of the transport domain, delivery of material resources and finished products, transportation of passengers using public and personal transport are provided that in total makes this domain one of the most important ones for socio-economic development of the country. Reduction of the number of road accidents and the population perished as a result of them might be provided by wide spread of up-to-date digital software complexes, and also on account of data exchange between transport and digital infrastructure on the basis of remote action. Analysis of the practice of application of automatic photo and video fixation of traffic violations in Russia is made in the study and also stage-by-stage development of these devices is evaluated as well as the main faults of their functioning are detected.As a result of the research work conducted, to improve identification of transports by digital complexes of automatic photo and video fixation, the authors of the article have proposed own technical solutions, prepared the list of their functional capabilities and proposed the method of interaction between information and analysis system with transports.

Keywords-devices of automatic photo and video fixation, information and analysis system, telematic technologies, data and telecommunication technologies, method of radio frequency identification, RFID-transponder

\section{INTRODUCTION}

Improvement of the transport domain upon development conditions of the digital economy concept and formation of "smart cities" is inseparably connected with all-around integration of digital technologies, control systems and complexes. Development of the transport domain goes via the route of improving of safety and ecological properties of its functioning, acceleration of cargo and passenger transportation processes. In course of gradual integration of up-to-date technologies, smart transport control systems are being created. By estimates of experts, the world market of the digital infrastructure will increase up to $25.1 \mathrm{bln}$. USD by the year 2024 from 5.1 bln. USD in 2015 [1]. One of the key directions of digitalization of the transport domain, apart from public transport and improvement of transport means (TM) themselves is generation of smart transport systems (STS) based on achievements in science and technology.

The first elementary STS systems appeared abroad already in 1950s, and within the past years, systems being part of STS were significantly improved: sensors of high accurate tracking, electronic information tables and technologies of automatic identification, navigation systems and video surveillance appeared [2]. Within the last decades, special attention in Russia was paid to the development of devices of automatic photo and video fixation which require permanent improvement of applied technologies to further increase traffic safety on account of detection of various traffic violations not dependant on weather and other conditions.

The factors of qualitative development of the transport domain in the area of automobile transport include speed and safety of cargo and passenger transportation to the destination. However, the trends of change of these two factors have mutually contradicting directions. Transportation speed increase leads to decrease of safety level, and, vice-versa, increase of safety level may be achieved on account of decrease in cargo and passenger transportation speed. Consequently, the above factors shall be taken into account and considered simultaneously when 
setting and achieving the goals on improvement of the country's transport system.

Furthermore, traffic safety should not be reduced exclusively to reliability and faultless functioning of automobile transport; it should be viewed much broader and be organically linked with the transport system as a whole. Additionally, one should take into account organizational, economic and technical and technological aspects of functioning of the transport complex of the country.

Increase of the level of auto-mobilization leads to deterioration of ecological conditions in the country, decrease of throughput capacity of road network, and, as a consequence, the increase of the level of emergency on the roads of the Russian Federation. In accordance with statistics, the level of auto-mobilization in the Russian Federation by 1 January 2019 makes 292 units for 1000 persons; at that, in 2018 about 165000 road accidents were registered [3]. Road conditions in cities become less and less comfortable: especially, it can be noted in megapolises both in Russia and abroad. Safe transport services are one of the most important factors defining the economic growth of the country, that's why provisioning of maximum efficiency of joint functioning of all the elements of the country's transport complex is an urgent task for scientific research and practical integration. We consider that development of digital tools for monitoring traffic during transportation contributes to increase of efficiency of motor transport industry of the country.

\section{MATERIALS AND METHODS}

To provide monitoring of the situation on roads in the world practice they most often specifically use the means of automatic photo and video fixation. Christie R., Böcher W. dealt with the development of means for monitoring of traffic during transportation; in their works they describe the problems of functioning of the means of automatic photo and video fixation abroad, and also propose a number of solutions for their elimination [4, 5]. Besides, one should note the works of Ferreira S., Hasan N. The first examined the development prospective of technical aids of monitoring of the traffic flow [6], and Hasan N. in his works described the development prospective of radio frequency identification, and also the feasibility of their application in various branches [7]. Foreign authors, namely V. Sai Prasanna, K. Kiran Kumar, Linganagouda R., in their works also examined the use of state-of-the-art control systems of motor transport to increase the level of traffic safety $[8,9]$.

For today, a number of digital complexes aimed at provision of traffic safety in the country's territory are functioning already. In recent time, smart transport systems have been widely spread which are aimed at informing transport drivers on the possible jams in the road network, weather conditions and many other factors with the use of special tables. Besides, more and more often they are using in the city the automated systems of traffic control aimed at regulating transport flows in real time mode. To provide the on-line control of transport flows and monitoring of traffic, they are intensely developing the systems of video surveillance providing exclusively monitoring of traffic in the road network. Furthermore, they are intensely integrating the means of automatic photo and video fixation of traffic violations; these means provide not only detection of traffic violations, but they can also be used as the means of transport flow monitoring.

All the above means are one of the components of a complex system aimed at provision of motor transport traffic safety in the country [10]. In our opinion, the most prospective direction in the development for the near period of time is usage of means of automatic photo and video fixation of traffic violations due to the fact that these means may simultaneously provide both violations of traffic rules (VTR) and monitoring of transport flows. Besides, these means presently contribute to decrease of the level of emergency on the roads of the Russian Federation, as for committed traffic violation a driver of the transport means is charged a fine that also has impact on him in the psychological aspect.

Integration of the means of automatic photo and video fixation was started within the framework of implementation of the Federal targeted programme "Improvement of Traffic Safety in 2006-2012" [11]. As a result of analysis of practice of usage of these means, one can make a conclusion that their integration in the Russian Federation territory contributes to increase of the level of discipline among the drivers. In the Federal targeted programme "Improvement of Traffic Safety in 2013-2020" one of the tasks is also provision of cargo and passenger transportation safety with the use of automatic means of photo and video fixation [12].

Development of means of automatic photo and video fixation of administrative violations with step-by-step broadening of their functional capabilities in the Russian Federation is given in Fig. 1.

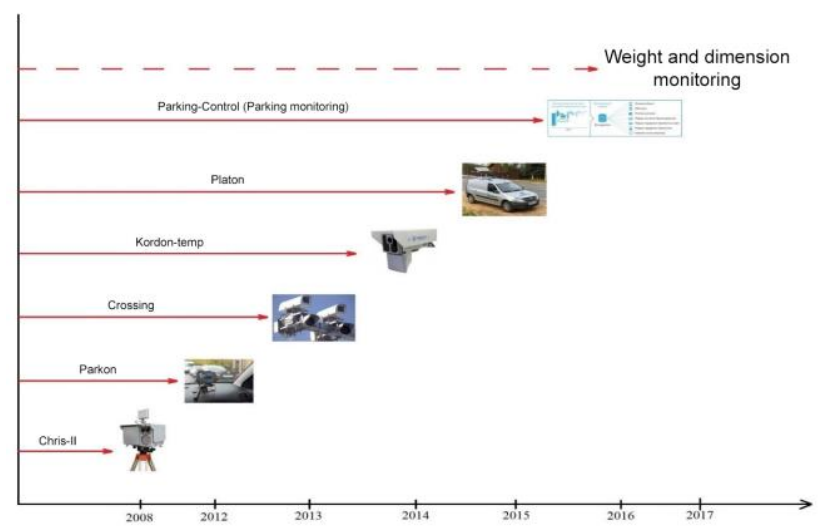

Fig. 1. Development of digital tools of automatic photo and video fixation in the Russian Federation..

Thus, the application of systems of automatic photo and video fixation provides implementation of tasks on transport flows monitoring and detection in them of transports violating traffic rules that requires increase of the level of identification of transport state registration signs. The technical solution proposed in this work on improvement of digital tools in the area of the systems of automatic photo and video fixation contributes to solving the problem of functioning of these systems under unfavourable conditions and also creates the basis for more accurate as well as qualitative detection of traffic violations as part of complex STS systems. 


\section{RESULTS}

Studying the foreign countries' experience testifies to the fact that the most prospective direction on digital technologies integration in the transport domain is development of multi-purpose complexes implementing a number of functions simultaneously: informing the driver on probable obstacle on the way of further motion, search of stolen transports, informing on emergency braking of cars going in front etc. [4-7].

On the basis of Saint Petersburg State University of Architecture and Civil Engineering, a number of research works were conducted regarding the use of automatic photo and video fixation means (Chris-S, Skat-P). As a result, a number of deficiencies of the existing complexes were detected, whose main disadvantage is the low level of identification of state registration signs (SRS); identification of SRS systems is less than $40 \%[13,14,15]$. To raise the level of SRS identification of transports, it is necessary to use the method of automatic identification providing detection of object at big distances and not depending on weather conditions. To integrate such a solution, the method of radio frequency identification was proposed due to the fact that only in this case there is a feasibility to change the identifier data. As a consequence, such a feature makes this method more preferable than others $[16,17]$. Apart from this, this method has the following advantages:

- high level of identifier strength;

- feasibility of integration of identifier in the structure of transport;

- high rate of data transfer;

- feasibility of detection of several objects which are simultaneously situated in the reader coverage area [18].

To integrate this technical solution, it is necessary to equip each transport with the RFID-transponder and to install the reader into the body of software and hardware complex. For that, it is necessary to use the long-range RFID-system operating within microwave range $868 \mathrm{MHz}$ and microwave band frequencies 2.5 and $5.8 \mathrm{GHz}$, and also to use active transponder with the recording method R/W (Read/Write) [19].

On the basis of stated technical solution, it is proposed to develop information and analysis system on interaction of smart onboard transport systems with the means of automatic photo and video fixation with the use of the radio frequency identification. The proposed technical solution on interaction of information and analysis system with transport is shown in Fig. 2.

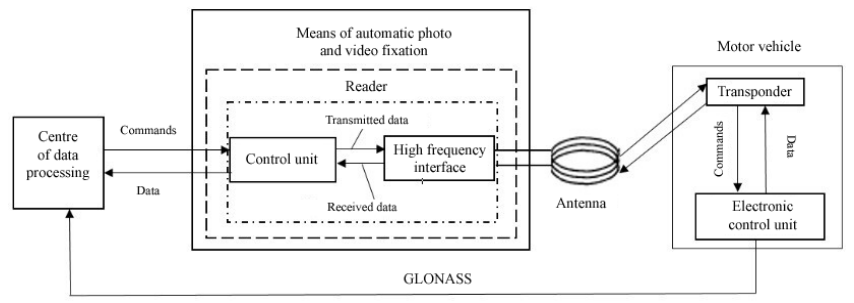

Fig. 2. Interaction of the proposed digital tool with transport.
The solution proposed is in transfer of commands from the centre of data processing to the means of automatic photo and video fixation. The reader transmitter emits electromagnetic field of a certain frequency via antenna. Transponder in the area of reading field coverage detects a signal from the reader and responds with own signal containing the necessary data at the same frequency. The signal is trapped by reader's antenna; data is decoded and transmitted to the centre of data processing. Besides, there is a feasibility of feedback between transport and the centre of data processing, which can be implemented by using GLONASS. In accordance with changes introduced in the order of the Ministry of Internal Affairs of Russia dated 11 November 2015, No. 1072/3557/2293, from 1 January 2017 all transports put into circulation shall have "special marks" carrying information on transport identification number with the purpose to call emergency field services in case of disaster. Usage of GLONASS will contribute to speeding up the response time of emergency field services that will allow to decrease the death rate on roads.

On the basis of proposed technical solutions, creating data and analytical system of interaction of smart onboard transport systems with the means of automatic photo and video fixation will allow to implement a number of functions (Figure 3).

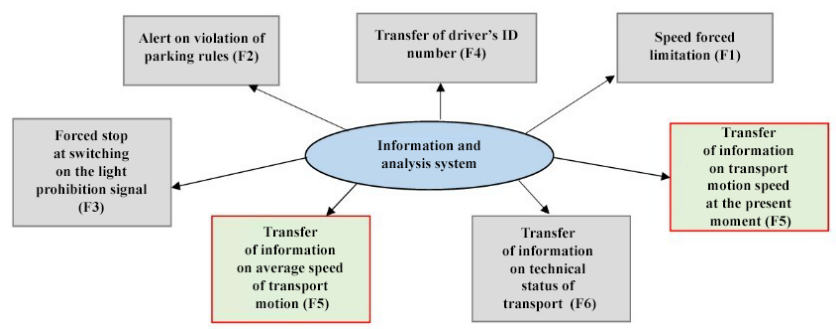

Fig. 3. The probable set of functions of the digital tool proposed.

On the basis of proposed technical solutions and the probable functional set of the proposed tool, mechanism of interaction between transport and software complex has been developed. It is shown in Figure 4.

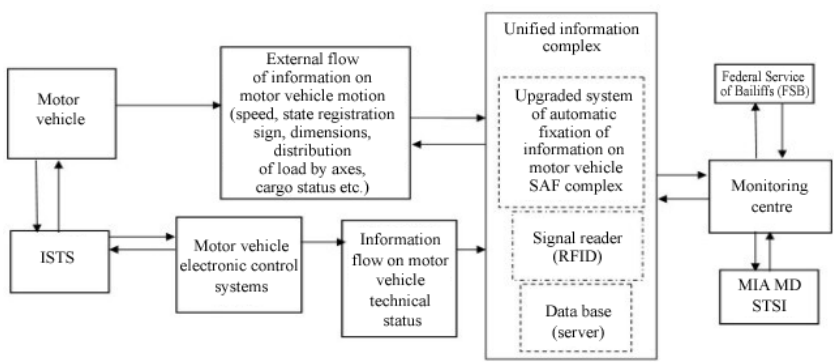

Fig. 4. The mechanism of interaction of information analysis system with transport.

This mechanism is in bilateral exchange with external and internal information flows between the proposed software complex and transport [20-22]. To integrate the proposed solutions, it is necessary to improve the existing means of automatic photo and video fixation on account of installation of RFID-marks into the reader body that will allow to carry out data flow transmission not only from transport to software complex, but vice-versa, have impact 
on transport on account of transmission of various commands to the control unit.

\section{Discussions}

STS systems have broad functionality, and their usage provides opportunities to charge fines for usage of paid highways and high speed road sections, track public transport and special equipment, inform drivers on weather conditions and situation on roads, determine automatically weight and dimension factors to define the transport category and correspondingly charge [23] and also control in complex the automobile flows on account of integration of "smart" traffic lights, monitoring sensors and means of automatic photo and video fixation [24]. For today, various means of automatic photo and video fixation are used in Russia. With the use of existing complexes, instantaneous speed of motion of transport, average transport motion speed at the monitored section are detected, and also pedestrians passing at unmonitored crossing, passage against prohibition light signal, going out beyond stop-line, crossing the solid line of road marking, and other violations. However, one should note that mainly means of automatic photo and video fixation are used which only detect exceeding of instantaneous speed of transport motion.

The lack of wide spreading of other complexes may be substantiated by the fact that with the existing technical support it is very difficult to detect transport violations, and also prove the drivers' guilt. The main problem is that quite often weather conditions, availability of other objects in registered shots, and also intentional distortion of the state registration sign do not give a chance to precisely define its contents that does not allow issuing resolution on administrative violation to the guilty person driving the transport. All these factors create the sense of impunity for committed traffic violation with the drivers that is why for today it is necessary to take cardinal measures to improve the means of photo and video fixation which will allow to record transports with high accuracy at any time of the day independently from weather conditions.

Upon conditions of generation of "smart cities", investments into digital transformation of various domains, including transport infrastructure, are more profitable if compared to investment of assets into traditional infrastructure projects [25].This fact is due to synergetic effect from joint usage of the majority of digital systems and complexes within the framework of single information and communication system of the city. As a whole, modern cities in developed economies are not widening their infrastructure, but only improve the already existing ones and applied technologies. The main advantages from development of digital technologies in the area of creation of smart transport systems are:

- long-term decrease of expenses on functioning of transport digital systems;

- increase of efficiency of solving the ecological, socioeconomic and other problems occurring due to urbanisation;

- investments into prospective and long-term tasks on complex improvement of the country's infrastructure.

\section{CONCLUSIONS}

By forecast of experts, by the year 2050, 3/4 of the planet population will dwell in cities (presently, this factor reaches $1 / 2$ of the population), the number of cars on roads will grow up to 2.5 bln. (against 1.1 bln. in 2011) [25]. The technologies of "smart city" will be used in the near future both during development of new territories around the existing agglomerates and within the framework of modernisation of cities' infrastructures. An important element of the "smart city" is safe transport infrastructure that is provided by complex improvement of applied digital technologies and complexes in this domain.

Analysis of existing digital tools of automatic photo and video registration has been conducted in the research work; as a result, the main faults of their functioning have been detected. The authors defined that the quantity of identified transports at the existing technical support makes only about $40 \%$.

As a result of the research work upgrading of existing technical aids of transport motion monitoring has been proposed. Description of functionalities of the technical solution developed is given, and also algorithm of interaction of the proposed information and analysis system with transports in the road network.

Integration of developed algorithm will provide increase of the level of identification of transports approximately up to $90 \%$, and will also raise the level of information interconnection between transports and the infrastructure. Usage of such complexes will provide necessity of punishment for committed administrative violation by transport drivers, and, as a consequence, will lead to decrease of the emergency level in the road network that will raise traffic safety level.

\section{ACKNOWLEDGMENT}

The article was prepared as part of the work on the grant of the President of the Russian Federation NSh-4028.2018.6

\section{REFERENCES}

[1] Navigant forecasts global smart urban mobility market to hit $\$ 25.1$ billion in 2024, Green Car Congress, 2015, https://www.greencarcongress.com/2015/06/20150624 navigant.html\#more.

[2] Issues Paper On Smart Cities and Infrastructure, United Nations Commission on Science and Technology for Development Intersessional Panel 2015-2016, 2016, https://unctad.org/meetings/en/SessionalDocuments/CSTD_2015_Iss uespaper_Theme1_SmartCitiesandInfra_en.pdf.

[3] Statistic data of road traffic accidents in the Russian Federation, http://stat.gibdd.ru.

[4] W. Böcher, Verkehrsaufklärung und Verkehrserziehung, Traffic Safety Campaigns and Traffic Safety Education, In Hilse, H.-G. \& Schneider, W (Ed): Verkehrssicherheit. Handbuch zur Entwicklung von Konzepten, Traffic Safety. Manual for Development of Concepts. Stuttgart u. a.: Boorberg, p. 248-299.

[5] R. Christie, Off-Road Facilities for Traffic Safety Education \& Novice Driver Training: A Cautionary Tale, Record of Conference Proceedings CD-ROM: Local Government Road Safety Conference (VicRoads: Kew, Victoria).

[6] S. Ferreira, A. Couto, Categorical Modeling to Evaluate Road Safety at the Planning Level, Journal of Transportation Safety \& Security, No. 4, 2012, pp. 308-322. 
[7] N. Hasan, Roadmap for RFID Implementation in Libraries: Issues and Challenges, International Journal of Information, Library and Society, vol. 3(1), 2014, pp. 65-71.

[8] V. S. Prasanna and K. K. Kumar, "Automated Efficient Traffic Control System in Real Time Applications," Indian Journal of Science and Technology, vol. 9(30), 2016, pp. 1-5.

[9] R. Linganagouda, "Automatic Intelligent Traffic Control System, International Journal of Advanced Research in Electrical, Electronics and Instrumentation Engineering," vol. 5(7), 2016, pp. 5902-5906.

[10] GOST R 56829-2015 Smart transport systems. Terms and definitionshttp://docs.cntd.ru/document/1200128315.

[11] Decree of the Russian Federation Government dated 20 February 2006 No. 100 "On Federal Target Programme "Improvement of Traffic Safety in 2006-2012", https://base.garant.ru/189189/.

[12] Decree of the Russian Federation Government dated 03 October 2013 No. 864 "On Federal Target Programme "Improvement of Traffic Safety in 2013-2020", https://mvd.ru/upload/site1/folder_page/010/469/824/PP_864_ot_03_ 10_2013.pdf.

[13] A. V. Marusin, V. F. Glazkov, R. N. Safiullin, M. A. Kerimov and A V. Marusin, "To substantiation of the model of selection of traffic violations automatic recording means, Urgent problems of traffic safety: materials of the international scientific and practical conference of students, postgraduates, young scientists and doctoral students," Saint-Petersburg: SPbGASU, 2015, 166-169.

[14] A. Marusin, A. Marusin and I. Danilov, "A method for assessing the influence of automated traffic enforcement system parameters on traffic safety," Transportation Research Procedia, 36, 2018, pp. 500506, https://doi.org/10.1016/j.trpro.2018.12.136.

[15] A.V. Marusin, "A method of assessing efficiency of functioning of the systems of automatic recording of traffic violations, dissertation for the degree of Doctor of Science," Saint-Petersburg, 2017, p. 160.

[16] A.V. Shemiakin and A. A. Kuraksin, "A procedure of studying characteristics of transport flow in the central part of Ryazan on the basis of technologies of global satellite positioning," Science and technology, No. 4, 2016, pp. 91-99.

[17] M. Kerimov, R. Safiullin, A. Marusin and A. Marusin, "Evaluation of Functional Efficiency of Automated Traffic Enforcement Systems, Organization and Traffic Safety Management in Large Cities,' SPbOTSIC-2016: 12th International Conference, St. Petersburg, Russia, 28-30 September 2016, pp. 288-294.

[18] V.L. Dhshunyan and V.F. Shan'gin, "Electronic identification. Noncontact electronic identifiers and smart cards," Moscow: Publishing house AST OOO, NT Press Publishers, 2004, p. 695.

[19] A.V. Marusin, I.K. Danilov, A.V. Marusin and I.V. Vorozheikin, Prospective technical solutions of transport motion monitoring during transportation, Civil engineers bulletin, No. 6 (65), 2017, pp. 285290.

[20] R.N. Safiullin, A.A. Karapetyan and I.V. Vorozheikin, "Information and analysis system of interaction of information safety of telecommunication systems (ISTS) of automobile equipment with automatic fixation means, Alternative power sources on automobile transport: collection of scientific articles," Voronezh Forest Technical Academy, Voronezh, 3, 2016, pp. 306-310.

[21] A. V. Marusin, M. A. Kerimov, R. N. Safiullin and A.V. Marusin, "Simulation of influence of various factors defining functioning of traffic monitoring systems in the Russian Federation regions, Urgent issues of transport in modern conditions: collection of scientific articles on materials of II International Scientific and Practical Conference," Saratov: Right-EXPO Publishing House, 2016, pp. 187 190.

[22] N.V. Pen'shin, "Technique of provisioning automobile traffic safety: schoolbook," Tambov: TGTU FGBOU VPO Publishers, 2013, p. 456.

[23] T. H. Ablyazov and A.V. Marusin, "State and private partnership as a mechanism of development of transport infrastructure upon conditions of generation of digital economy," Economic relations, vol. 9(2), 2019, doi: 10.18334/eo.9.2.40593.

[24] Smart City, CROC, https://www.croc.ru/solution/businesssolutions/smart-city/smart_transportation/.

[25] Ernst \& Young, Connecting the cities of the future: smart transport infrastructure, 2016, https://consulting.ey.com/connecting-citiesfuture-smart-transport-infrastructure/. 